Send your research letters to the editor, British Dental Journal, 64 Wimpole Street, LondonW1G8YS or by email to bdj@bda.org Priority will be given to letters less than 500 words long. Letters should be typed. Authors must sign the letter, which may be edited for reasons of space

\section{Dental priorities}

Sir, as in photography where cameras can be aperture priority, or, speed priority, I have come to the conclusion that Dental Practice within the NHS, can be 'patient priority' or 'business priority'. Patient priority practitioners will always put the interests of the patient first, business priority practitioners will always consider their bank balance first. I accept that there will be 'average' practitioners who endeavour to practice ethically whilst avoiding an overdraft at the bank, but, most practitioners will have an inclination towards one priority or the other.

Until now, this has been difficult to quantify. Recent publications from the Dept. of Health ${ }^{1}$ inform us that after joining a PDS pilot, practitioners' restorative treatment patterns decreased by about $10 \%$. In other words, when the pressure to practice in a 'business priority' mode was removed, and practitioners were free to practice in a 'patient priority' mode, their prescribing habits changed by $10 \%$. Thus, the new draft contract for the General Dental Services ${ }^{2}$, (Clause $13 \mathrm{~g}$ ) concludes: "In the period from 1st October 2005 to 30th September 2006 practices will be able to free up capacity of a minimum of $10 \%$ of weighted courses of treatment". Clauses $13 \mathrm{i}$ \& $13 \mathrm{j}$ go on to state: "NHS commitment will be measured as 95\% of weighted courses of treatment in the base year", "within that $95 \%$ of courses of treatment, practices will see at least 5\% more patients by 30th September 2006".

Some of us have always endeavoured to practice in a 'patient priority' mode. Our practice introduced a reserved one hour emergency period 20 years ago! We have always offered advice on diet, oral hygiene and preventive methods. We have always had a system of watching and reviewing early enamel lesions. We have always had a flexible patient recall system based on a risk assessment of the patient. We did not wait until there was no financial penalty for doing these!

It is now clear that the NHS has been penalising 'patient priority' practitioners by a minimum of $10 \%$ of gross income (or a minimum of $£ 10,000$ per annum of net income). By adopting historical financial data as the basis for the new contract, the Department of Health is ensuring that this penalty continues in the future. In addition, it would appear that facilities are being placed in the new contract to further penalise these practitioners when they are unable to achieve further savings and take on more patients, because they are already treating patients in a "patient priority' mode and have limited or no ability to alter their prescribing patterns further.

This contract is intended to be a 'fresh start'. The draft however, contains basic mistakes and false assumptions which will almost certainly ensure that practitioners, who have become disillusioned with the NHS and reduced their commitment to it, are certain never to return again.

\section{E. Byrne \\ Bedford}

1. NHS Dentistry: Delivering Change. Report by the Chief Dental Officer (England) July 2004 page 19.

2. Base Contract: Draft -subject to Agreement by GO PC \&t Minister. BDA web-site.

\section{Professor Raman Bedi, Chief Dental} Officer for England responds: Mr Byrne's letter raises some interesting misunderstandings with regard to the dental reforms. It is rather unfortunate that I have to disagree with the primary point your correspondent makes about dentists' priorities when treating patients. I believe that the vast majority of practitioners put the needs of the patients first, providing good patient care while at the same time wishing to maintain a reasonable level of earnings, consistent with their training and personal investment in their practices. The current item of service system does tend to focus the mind on individual fees, which is the reason that we wish to get away from it in our current reforms. Our PDS pilots and Modernisation Agency field sites confirm our belief that when the subconscious drivers of the item of service system are removed, the numbers of items of treatment provided fall by at least 10\%.

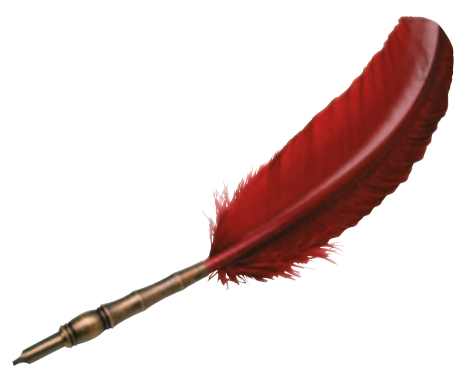

The new contractual arrangements and the Heads of Agreement document published on the BDA website in September 2004 showed that the government expected savings to be made in terms of time spent on intervention type treatment and intended to share those savings with practitioners.

I do not understand how we are "penalising practitioners by a minimum of $10 \%$ gross income", especially as we have given a very clear guarantee that gross income will be protected for a period of three years in return for a maintained NHS commitment. The sort of data contained within the Heads of Agreement document is to be provided to PCTs and dentists alike.

The document also says that if your NHS commitment - as measured by weighted courses of treatment-fell outside the agreed parameters then this would not trigger a reduction in contract value, but would trigger a discussion between the PCT and the contract-holder. If you were able to show that you were adopting these new ways of working prior to the introduction of the new contractual arrangements, then that could be agreed between you and the PCT and both sides would obviously be benefitting. The intention of this legislation is to make the NHS a more attractive place for dentists to work and to ensure that taxpayers get a better return on the major investment they make in NHS dentistry by delivering the most appropriate patient-led service.

The current demand from dentists to move into early PDS is enormous. We expect to have $25 \%$ of practices in pilot arrangements by early April 2005, and more applications are coming in daily.

It seems that the profession as a whole does see the advantages of the new ways of working, appreciates the benefit that working in the NHS can bring - for example, the NHS pensions scheme, maternity pay, free Continuing Professional Development and, as the service develops, closer integration with the rest of the NHS and involvement with NHS-funded capital developments. doi: 10.1038/sj.bdj.4812290 


\section{Contradictory literature}

Sir, Dr Ahearne raises an important point regarding the problem of evaluating contradictory literature ${ }^{1}$. Clinical trials are limited by both the nature and size of the study or sample population.

The most important evidence that the results of such studies provides can often only be applied to a more general population than the subjects in the study represent. Thus, the conclusions from Moore et $a l^{2}$ can only be related to a population that has the same characteristics as those recruited: in this case, a South London group of subjects with a prevalence of disease representative of most UK populations.

As stated in the paper, these results are not consistent with those previously published regarding populations studied in the USA which were drawn from groups with a much higher prevalence of severe disease. Differences in the study populations may also explain the conflicting results between Moore et al ${ }^{2}$ and Radnai et $a l^{3}$.

A second potential reason for differences arises from the numbers of subjects and type of study. In the studies referred to by Dr Ahearne, the contrast was between a large prospective study ${ }^{2}$ and a small case-control study described as a pilot study ${ }^{3}$. Evidence-based public health and clinical dentistry must be based on well-conducted research, but no single clinical trial can produce conclusions related to all people in all places all of the time. This can only be approached through systematic review of a number of published clinical trials. Unfortunately, for many clinical questions, no such conclusive evidence exists, and practitioners must weigh carefully the evidence that is available (be it research papers, reviews or clinical experience) and judge its relevance to their own clinical situation. No one said evidence-based dentistry was easy!
S. Farrell neé Moore
M. Ide
R. Wilson
London

1. Ahearne J. Evidence based dentistry Br Dent J 2004; 197: 594

2. Moore $\mathrm{S}$, Ide M, Coward PY, Randhawa M,
Borkowska E, Baylis R, Wilson R F. A prospective study to investigate the relationship between periodontal disease and adverse pregnancy outcome. BrDent J 2004; 197: 251-258.

3. Radnai M, Gorzo I, Nagy E, Urban E, Novak T, Pal A. A possible association between preterm birth and early periodontitis. A pilot study. J Clin Periodontol 2004 31: 736-741.

\section{doi: 10.1038/sj.bdj.4812291 \\ Dental prescribing}

Sir, there appears to be some confusion about recent and future changes to prescribing arrangements for dentists, and we would like to clarify the situation. The current British National Formulary (BNF 48) was issued in September 2004. This contains the dental list, which lists all medicines that dental practitioners can prescribe on the NHS. Dental practitioners cannot currently prescribe on the NHS any medication which is not included on the dental list.

However, the aim remains to abolish the dental list and to allow dental practitioners greater access to the BNF. Further changes are due to be implemented in April 2006, and all dentists will be informed of the exact date before implementation.

There is also some debate over whether the BNF is providing up-to-date advice on endocarditis prophylaxis. The BNF continually monitors new information in order to keep the text as up-to-date as possible. In updating text, the BNF takes into account both current evidence and clinical practice.

The Editorial Staff of the BNF are aware of recent recommendations from a working group of the British Cardiac Society (BCS) Clinical Practice Committee and the Royal College of Physicians (RCP) Clinical Effectiveness and Evaluation Unit on "Dental Aspects of Endocarditis Prophylaxis". These recommendations were issued during the preparation of BNF 48 and were reviewed in detail by the Dental Formulary Subcommittee.

The Subcommittee felt that the recommendations went beyond the evidence available and was also concerned about how practicable their implementation would be. The Subcommittee agreed that the BNF would not be changed to reflect these recommendations. However, the BNF 48 does acknowledge the existence of the alternative recommendations, on $\mathrm{p}$ 23: "The recommendations of a Working Party of the British Society for Antimicrobial

Chemotherapy (BSAC) are reflected in Table 2, Section 5.1. Alternative guidelines have been produced and may be in use in some settings."

The BSAC is currently reviewing the recommendations and the BNF and its advisers will continue to keep endocarditis prophylaxis under close review.

We hope that this clarifies the current situation.

S. Carruthers

\section{H. Edmondson}

By email

doi: 10.1038/sj.bdj.4812292

\section{Deciduous molars}

Sir, Messrs Foley, Evans and Blackwell (BDJ 2004, 197: 697) have given me great pleasure in their study of the restoration of deciduous molars - especially in their use of Black Copper Cement (BCC). In Manchester in 1950 we had studied a variety of topical methods to prevent dental caries - I must say without success ${ }^{1}$.

We found that BCC was an excellent fissure sealant for first permanent molars but which required renewal every six months. We did not publish these results on account of the temporary nature of the sealant. We did not use it for restoring deciduous molars as the acid from the $\mathrm{BCC}$ caused pulpal irritation. We later discovered the multiplicity of root canals in deciduous molars which could convey the acid to the pulp ${ }^{2}$.

As students we had been taught to line all cavitities before using silicate restoration on account of the free acid later we found the reason - the possible presence of 'giant tubules's.

I have not been surprised that in the Dundee study some pulpal problems occurred. BCC (Ames) was a blessing for first permanent molars in the days before modern sealants.

\section{J. Miller \\ Cardiff}

1. J. Miller Br Dent J 1951: XCI: 92-98

2. R. K. Woo, J. Miller. J Int Ass Dent Child 1981: 12 51-57

3. J. Miller. J Dent Child 1981: 269-271

doi: 10.1038/sj.bdj.4812293 